\title{
Pore Wetting and Its Effect on Breakthrough Pressure in Water-Wet and Oil-Wet Pores
}

\author{
Xingxun Li and Xianfeng Fan
}

\begin{abstract}
Pore wetting plays an important role on enhanced oil recovery because of its effects on fluid saturation, flow behavior and displacement breakthrough pressure of reservoir fluids in porous medium. This paper aims towards measuring contact angles of alcohol aqueous solutions and breakthrough pressures required for air displacing alcohol aqueous solutions in a single micro-size water-wet pore and oil-wet pore. The liquids used are methanol, ethanol, 1-propanol aqueous solutions which could represent the fundamental components of surfactant solutions used in surfactant flooding process. The pores used are silica pores and PMMA pores, which simulate water-wet pores and oil-wet pores in the oil reservoirs. Our results indicate that the contact angle of alcohol aqueous solutions in a silica pore and PMMA pore decreases when the concentration of alcohol increases before reaching CMC. The contact angle decreases more dramatically with the alcohol concentration in an oil-wet pore than in a water-wet pore. The breakthrough pressure increases linearly with the surface tension in the water-wet pore. However, in the oil-wet pore, the breakthrough pressure stops increasing with surface tension when the surface tension is larger than around $35 \mathrm{mN} / \mathrm{m}$.
\end{abstract}

Index Terms-Enhanced oil recovery, displacement, multiphase flow, pore wetting.

\section{INTRODUCTION}

Multiphase flow transport in porous media is relevant to many problems of great scientific and industrial importance, such as ceramic, coating, printing, detergency, groundwater movements, nanofluidics and nanolubrication extraction of oil, gas and geothermal energy from underground reservoirs, $\mathrm{CO}_{2}$ storage and transport of contaminants in soils and aquifers [1]-[8] Immiscible fluids migration in a pore is actually a displacement process, which is not only governed by the physical and chemical properties of fluids but also more importantly depends on the pore wetting [9]-[13]. Pore wetting of an oil reservoir controls how and where fluids flow and reside in the oil reservoir and determines the displacement efficiency for oil recovery. The original wetting condition of most of reservoirs and aquifers is predominately considered as being water-wet, but it is now widely believed that the most of reservoirs are actually mixed-wet. The origin of mixed wettability has been widely studied [14]-[18]. Some of reservoirs are water-wet and altered to be oil-wet during oil production [19]. This wetting inconsistency could severely affect the rheological properties of reservoir fluids in porous

Manuscript received November 11, 2013; revised January 5, 2014. This work was supported in part by Carnegie Scholarship, UK and The University of Edinburgh research scholarship.

The authors are with the Institute for Materials and Processes, School of Engineering, The University of Edinburgh, UK (e-mail: X.Li@ed.ac.uk, X.Fan@ed.ac.uk). reservoir rocks and influence the multiphase flow displacement efficiency during the oil exaction in surfactant flooding process [20]-[22]. So, it would be necessary to investigate the wetting and displacement of liquids in both water-wet pore and oil-wet pore. We have experimentally studied static and dynamic pore wettabilities in terms of the effects of pore size, surface tension and viscosity of liquid [23], by measuring the contact angle of liquid in a small pore instead of the traditional contact angle measurements on a flat substrate [24]. In this paper, we measured the contact angles of alcohol aqueous solutions and the breakthrough pressures of air displacing alcohol aqueous solutions in a silica pore and a PMMA pore. The silica and PMMA are hydrophilic and hydrophobic materials, which represent the water-wet and oil-wet pores, respectively. The obtained results could advance the understanding of multiphase flow transport in porous media.

\section{Methods AND MATERIALS}

\section{A. Experimental Methods}

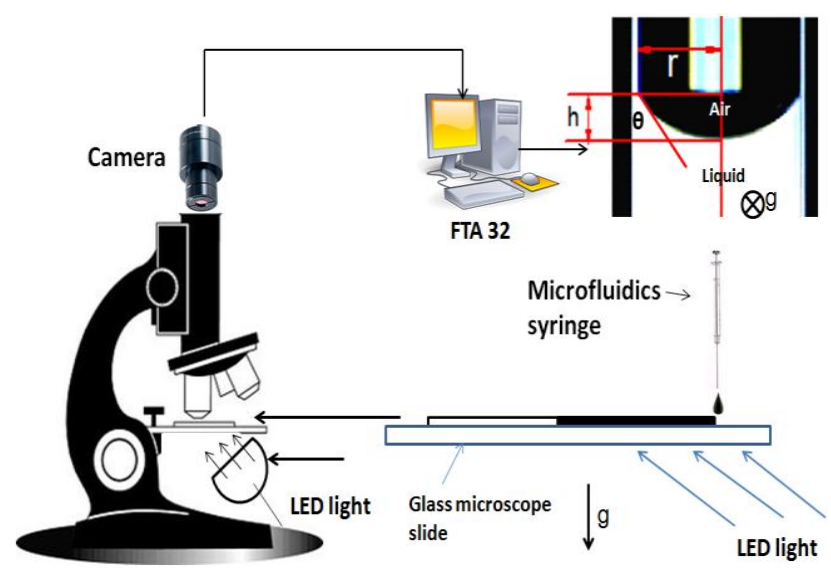

Fig. 1. Experimental setup for the study of contact angles in a capillary.

Fig. 1 shows the contact angle measurement in a capillary. An optical microscope (Olympus, BHW) with a $10 \mathrm{X}$ objective (M PLAN 10X (025)) equipped with a digital camera (AM7023, Dino-Eye) was uses to image the liquid meniscus. Due to the fact that the quality of meniscus image of a small volume of liquid in a capillary highly depends on the measurement method and light source, a LED light source was placed under the glass capillary. The light travels from the liquid end up to the meniscus in a dark background to overcome the degree of image distortion when a cylindrical capillary is used and therefore facilitate the measurements [25]. The outermost boundary of liquid-gas interface was well lighted and focused to produce the clear two-phase interfacial 
line [26], [27]. During the measurement, a single cleaned capillary was placed on a glass slide support and focused by microscope. A small portion of liquid $(\sim 1 \mu \mathrm{L})$ was dropped onto one end of the capillary using a microfluidic syringe (Hamilton, 701ASN $10 \mu \mathrm{L}$ ). The liquid was then imbibed into the capillary by its own capillary force. When the spontaneous dynamic imbibition was completely stopped and the equilibrium status was reached in the capillary, the equilibrium/static contact angle was achieved. To obtain the contact angle of liquid in a pore, we analyzed the microscopic images by using the method recently proposed by Cheong $e t$ al. [25]. Cheong et al. developed a method of measuring the contact angle of small volumes, by only using the capillary radius $(r)$ and meniscus height $(h)$ (see Fig. 1) of the capillary meniscus as shown in equation (1).

$$
\theta=\tan ^{-1}\left(\frac{r^{2}-h^{2}}{2 r h}\right)
$$

where $\theta$ is the contact angle in a pore, $r$ is the radius of capillary and $h$ the height of capillary meniscus.

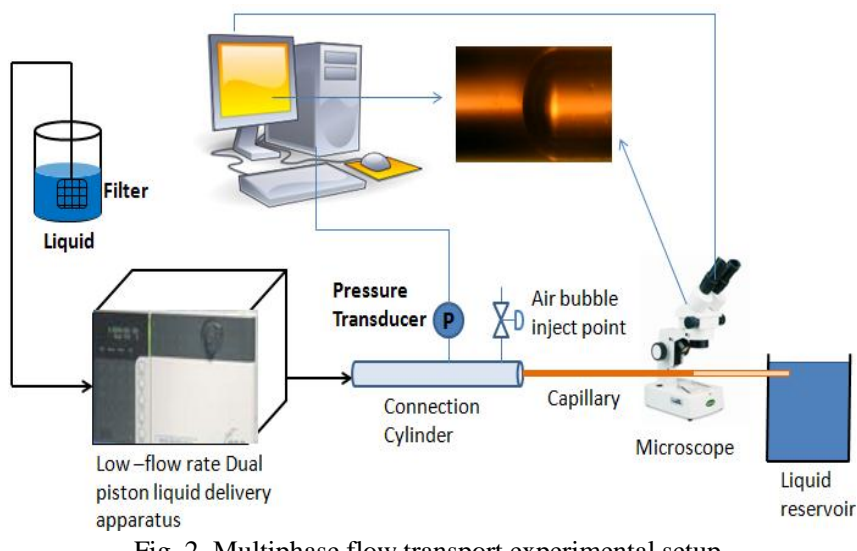

The experimental setup shown in Fig. 2 is designed to measure the capillary resistance of driving a two-phase flow through a single capillary tube to study the transport of multiphase flow in a single pore. The liquid was first pumped to the capillary by a Solvent Delivery Unit (LC-2AD, Shimadzu) at a flow rate of $0.005 \mathrm{ml} / \mathrm{min}$. The end of capillary was connected to the liquid reservoir so that the effect of end-effect drag can be eliminated. When the liquid flow in the capillary reaches steady state, the air is injected at the connection cylinder in order to introduce the air-liquid interface in the capillary. The pressure for driving air-liquid was measured by a pressure transducer with a resolution of 0.1 mbar (DPI 280, Druck).

Fig. 3 shows the displacement pressure profile of air displacing DI water through a silica capillary with a size of $250 \mu \mathrm{m}$. For the section O-A, the air-water interface does not enter the capillary. The flow in the capillary is solely DI water in one phase. The driving force is balanced by the viscous resistance of water movement. The differential pressure stays around at 0 . At point $\mathrm{A}$, the air-water interface starts to enter the capillary and intends to break through the capillary. When a two-phase interface is introduced into a small capillary, the capillary resistance would dominate. Thus, a larger driving force is required to overcome the capillary resistance. When the displacement pressure is accumulated to the peak point $\mathrm{B}$ which is around $13.5 \mathrm{mbar}$, the driving force is large enough to drive the air-water interface break through the capillary. The pressure at point $\mathrm{B}$ we defined as capillary breakthrough pressure. At the peak point B, the two-phase interface comes out from the capillary and pressure drops drastically to $C$ and returns to the pressure value in section O-A. It is worth to note here that the driving force of two-phase flow is significantly larger than that to one-phase flow in a capillary.

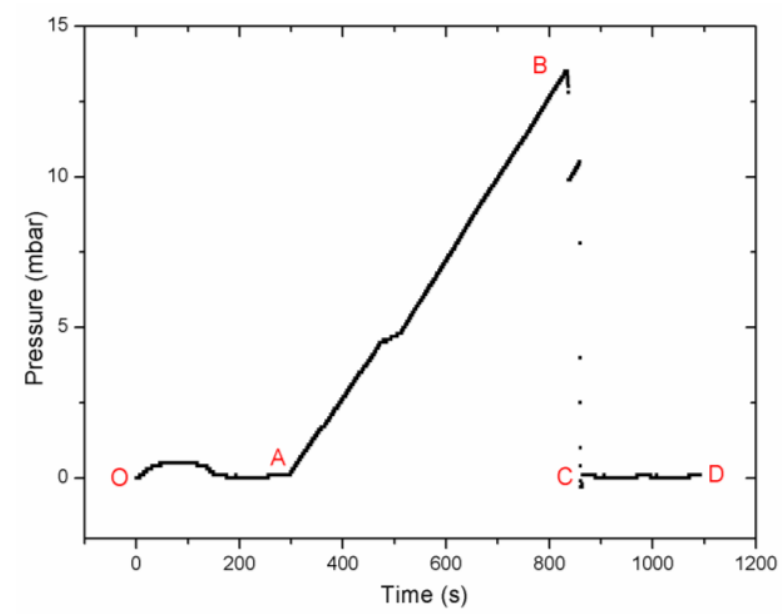

Fig 3. Displacement pressure profile for air displacing DI water in a silica capillary with a size of $250 \mu \mathrm{m}$ at $0.01 \mathrm{ml} / \mathrm{min}$ driving flow rate.

\section{B. Materials}

The pores used in this study are flexible fused silica capillary tube (TSP250350) and Acrylic PMMA (Poly(methyl methacrylate)) (PARADIGM), which are hydrophilic and hydrophobic pores, respectively. They can represent the water-wet pores and oil-wet pores in the reservoirs. The inner diameters of both capillaries are $250 \mu \mathrm{m}$. Considering the effect of surface tension of liquids on the displacement of two-phase flow through a pore, three kinds of alcohol aqueous solutions with different alcohol mass concentration fractions ranging from 0 to 1 were used in this study. The alcohols include methanol $\left(\mathrm{CH}_{3}-\mathrm{OH}\right)$, ethanol $\left(\mathrm{CH}_{3} \mathrm{CH}_{2}-\mathrm{OH}\right)$ and 1-propanol $\left(\mathrm{CH}_{3} \mathrm{CH}_{2} \mathrm{CH}_{2}-\mathrm{OH}\right)$. Table I lists the surface tensions of all alcohol aqueous solutions used in this study.

TABLE I: SURFACE TENSIONS OF ALCOHOL AQUEOUS SOLUTIONS

\begin{tabular}{cccc}
\hline \hline & \multicolumn{2}{l}{ Surface tension of alcohol aqueous solution $(\mathrm{mN} / \mathrm{m})^{\mathrm{a}}$} \\
\hline $\begin{array}{c}\text { Alcohol mass } \\
\text { concentration }\end{array}$ & Methanol & Ethanol & 1-propanol \\
\hline 0 & 72.75 & 72.75 & 72.75 \\
0.05 & 63.46 & 56.41 & 42.51 \\
0.1 & 56.87 & 48.14 & 34.86 \\
0.2 & 47.86 & 38.56 & 28.31 \\
0.3 & 41.09 & 33.53 & 26.41 \\
0.4 & 37.02 & 30.69 & 25.68 \\
0.5 & 33.37 & 28.51 & 25.18 \\
0.6 & 30.32 & 26.72 & 24.89 \\
0.7 & 27.91 & 25.48 & 24.47 \\
0.8 & 25.98 & 24.32 & 24.23 \\
0.9 & 24.37 & 23.23 & 23.98 \\
1.0 & 22.95 & 22.31 & 23.69 \\
\hline \hline
\end{tabular}

a The surface tensions of liquids were determined by pendant drop experiments (First Ten Angstroms). 


\section{RESULTS AND DisCUSSION}

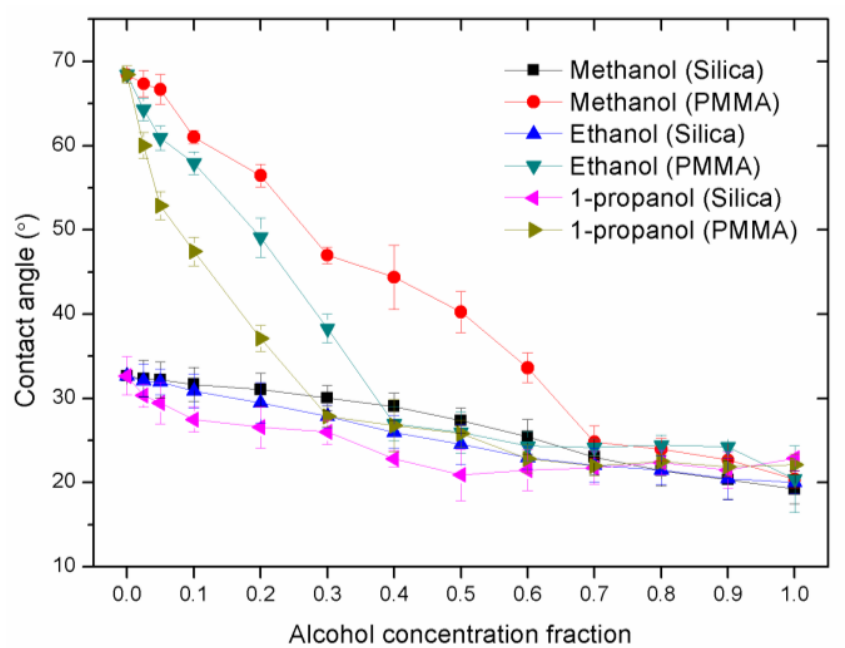

Fig. 4. Effect of alcohol concentration of alcohol aqueous solution on pore contact angles in a silica pore and a PMMA pore.

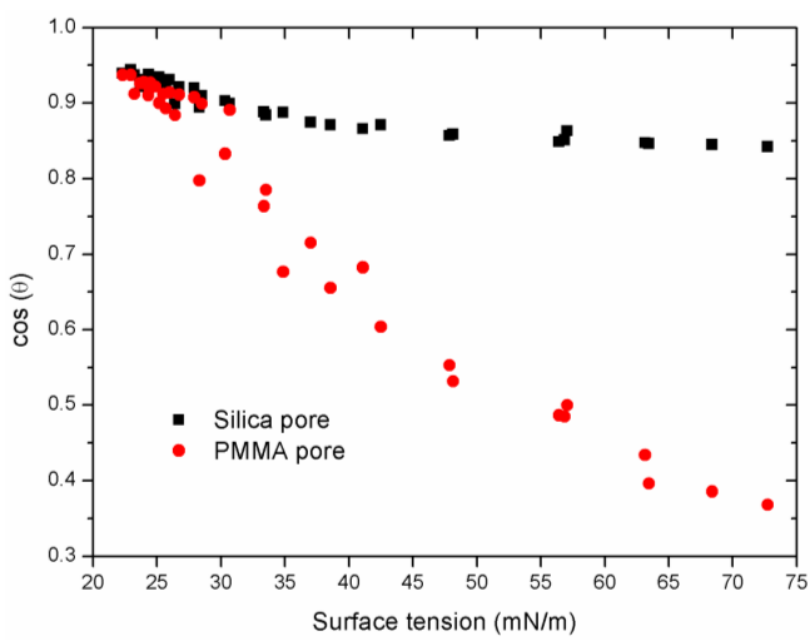

Fig. 5. Effect of surface tension of alcohol aqueous solution on pore contact angles in a silica pore and a PMMA pore.

Fig. 4 presents the contact angles of methanol, ethanol and 1-propanol aqueous solutions in single silica pores and PMMA pores, respectively. As all these different alcohols have one hydroxyl group at the terminal carbon but different lengths of carbon chains, the effect of concentration of amphiphiles with various alkyl chain lengths on pore wetting can be revealed. At the alcohol concentration of alcohol in alcohol aqueous solution of zero, the contact angle of alcohol aqueous solution is around $68^{\circ}$ in a PMMA pore and corresponds to contact angle of water. In PMMA pores, the contact angles of alcohol aqueous solutions dramatically decrease from $68^{\circ}$ with alcohol concentration increase before the alcohol concentration reaching its CMC (Critical Micelle Concentration). Beyond the $\mathrm{CMC}$, the contact angle stops decreasing and keeps around $20^{\circ}$. The three alcohols have different CMCs, in which 1-propanol has the lowest CMS of 0.4 and methanol has the highest CMC of 0.9. The contact angle of 1-propanol aqueous solution drops with the alcohol concentration most significantly and approaches to a constant at its CMC of 0.4 in a PMMA pore. By comparison, the contact angles of ethanol and methanol aqueous solutions vary with the alcohol concentration less significantly. They reach constant values at their $\mathrm{CMCs}$ of 0.6 and 0.9 respectively in PMMA pores.

The pore contact angle of water in a silica pore is around $33^{\circ}$, which is less than that in a PMMA pore by $35^{\circ}$. The effect of concentration of various amphiphiles on the pore contact angle is less significant than that on pore contact angle in a PMMA pore. The contact angles of alcohol aqueous solution decrease from around $33^{\circ}$ to $20^{\circ}$ from the alcohol concentration fractions of 0 to their CMCs. Their contact angles remains at $20^{\circ}$ beyond CMCs.

Fig. 5 plots the cosine of contact angles against surface tensions of all the alcohol aqueous solutions in a silica pore and PMMA pore based on the data in Fig. 4. This indicates that the trend of pore contact angle variation with the surface tension in a silica pore significantly differs from that in PMMA pore. The contact angle of alcohol aqueous solution varies with its surface tension in an oil-wet pore (PMMA) more remarkably than that in a water-wet pore (silica).

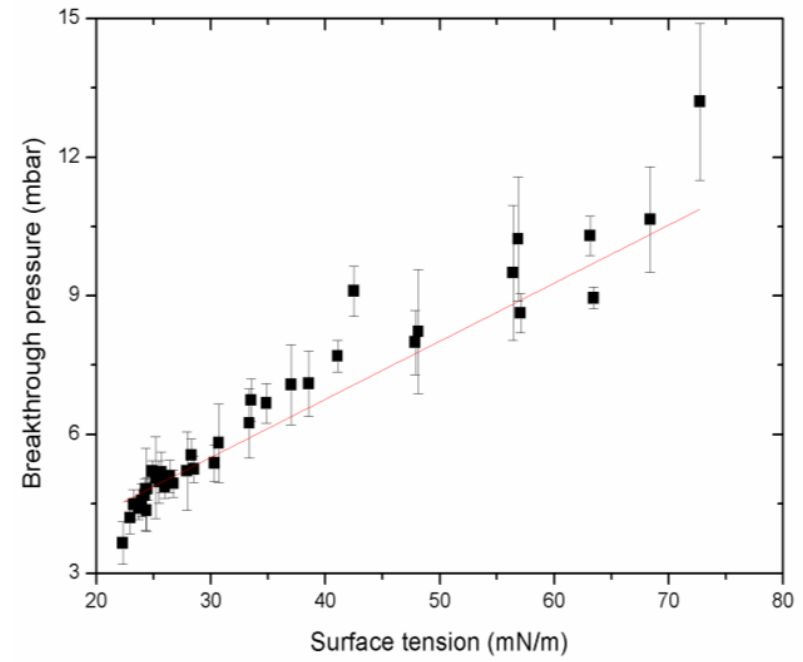

Fig. 6. Effect of surface tension on breakthrough pressures for air displacing alcohol aqueous solutions in a silica pore.

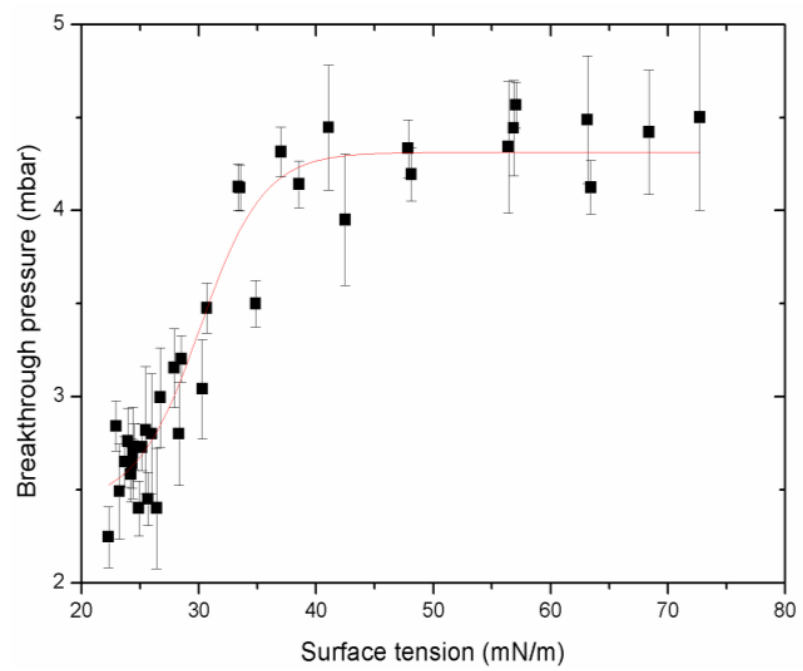

Fig. 7. Effect of surface tension on breakthrough pressures for air displacing alcohol aqueous solutions in a PMMA pore.

The breakthrough pressures required for air displacing alcohol aqueous solutions were measured in silica and PMMA pores, by considering the effect of surface tension (Fig. 6 and Fig. 7). The breakthrough pressure increases linearly with the surface tension in the water-wet pore (silica pore). However, in the oil-wet pore (PMMA pore), the 
breakthrough pressure stops increasing when the surface tension is higher than around $35 \mathrm{mN} / \mathrm{m}$. The breakthrough pressure is correlated with both surface tension $(\gamma)$ and contact angle $(\theta)$ according to the Young-Laplace equation $(\mathrm{P} \sim \gamma \cos \theta)$. Fig. 5 indicates that the dependence of contact angle $(\cos \theta)$ on the surface tension $(\gamma)$ of alcohol aqueous solution in a water-wet pore (silica) significantly differs from that in an oil-wet pore (PMMA). This does cause the different breakthrough pressure trends of air displacing alcohol aqueous solutions in a silica pore and PMMA pore.

\section{CONCLUSION}

Pore wetting and breakthrough pressure of alcohol aqueous solution were directly measured in water-wet pores and oil-wet pore in this study, respectively, by considering the effect of surface tension of liquid. The results can significantly advance the understanding of pore wetting and multiphase flow transport in porous media for enhanced oil recovery purposes. In our future studies, the pore wetting and breakthrough pressure of liquids will be measured in the pores with smaller sizes, and more amphiphilic organic compounds will be investigated, such as alkyl amines and alkyl carboxyl acids.

\section{ACKNOWLEDGMENT}

This work is supported by the Carnegie Trust for the Universities of Scotland, UK and The University of Edinburgh Research Scholarship.

\section{REFERENCES}

[1] A. M. Cazabat, "Wetting from macroscopic to microscopic scale," $A d v$. Colloid Interface Sci., vol. 42, pp. 65-87, 1992.

[2] P. G. de Gennes, "Wetting: statics and dynamics," Rev. Mod. Phys., vol. 57, pp. 827-863, 1985

[3] E. B. Dussan V., "On the spreading of liquids on solid surfaces: static and dynamic contact lines," Annu. Rev. Fluid Mech., vol. 11, pp. 371-400, 1979.

[4] A. B. A. Elyousfi, A. K. Chesters, A. M. Cazabat, and S. Villette, "Approximate solution for the spreading of a droplet on a smooth solid surface," J. Colloid Interface Sci., vol. 207, pp. 30-40, 1998.

[5] K. Ishimi, J. Mohri, H. Mukouyama, and H. Ishikawa, "Dynamic wetting and advancing contact angles in horizontal capillary tubes," $J$. Chem. Eng. Japan., vol. 31, pp. 914-921, 1998.

[6] G. Martic, T. D. Blake, and J. De Coninck, "Dynamics of imbibition into a pore with a heterogeneous surface," Langmuir, vol. 21, pp. 11201-11207, 2005.

[7] G. F. Teletzke, H. T. Davis, and L. E. Scriven, "How liquids spread on solids," Chem. Eng. Comm., vol. 55, pp. 41-82, 1987.

[8] G. F. Teletzke, H. T. Davis, and L. E. Scriven, "Wetting hydrodynamics," Revue Phys. Appl., vol. 23, pp. 989-1007, 1988.

[9] E. Aker and K. J. Måløy, "Simulating temporal evolution of pressure in two-phase flow in porous media," Phys. Rev. E, vol. 58, pp. 2217-2226, 1998.
[10] R. H. Brooks and A. T. Corey, Hydraulic Properties of Porous Media, State University Colorado State University Hydrology Paper 3. Fort Collins, CO, 1964

[11] P. S. Laplace, "Theory of capillary attraction," Supplements to the 10th book of "Celestial Mechanics" (1806, 1807), translated and annotated by N. Bowditch (1893), Paris, 1806.

[12] J. E. Seebergh and J. C. Berg, "Dynamic wetting in the low capillary number regime," Chem. Eng. Sci., vol. 47, pp. 4455-4464, 1992.

[13] T. Young, "An essay on the cohesion of fluids," Phil. Trans. Roy. Soc.Lond., vol. 95, pp. 65-87, 1805.

[14] J. S. Buckley, "Asphaltene precipitation and crude oil wetting," SPE Advanced Technology Series, vol. 3, pp. 53-59, 1995.

[15] J. S. Buckley, "Effective wettability of minerals exposed to crude oil," Current Opinion in Colloid \& Interface Science, vol. 6, pp. 191-196, 2001.

[16] P. P. Jadhunandan and N. R. Morrow, "Effect of wettability on waterflood recovery for crude-oil/brine/rock systems," in Proc. the 1991 SPE Annual Technical Conference and Exhibition, Richardson, TX, United States, 1991, pp. 111-126.

[17] P. P. Jadhunandan and N. R. Morrow, "Spontaneous imbibition of water by crude oil/brine/rock systems," In Situ, vol. 15, pp. 319-345, 1991.

[18] L. Yu and J. S. Buckley, "Evolution of wetting alteration by adsorption from crude oil," SPE Formation Evaluation, vol. 12, pp. 5-11, 1997.

[19] R. A. Salathiel, "Oil recovery by surface film drainage in mixed-wettability rocks," SPE Reprint Series, pp. 80-88, 2003.

[20] N. Aske, H. Kallevik, E. E. Johnsen, and J. Sjoblom, "Asphaltene aggregation from crude oils and model systems studied by high-pressure NIR spectroscopy," Energy and Fuels, vol. 16, pp. 1287-1295, 2002.

[21] H. Laux, I. Rahimian, and T. Butz, "Thermodynamics and mechanism of stabilization and precipitation of petroleum colloids," Fuel processing technology, vol. 53, pp. 69-79, 1997.

[22] K. Oh, T. A. Ring, and M. D. Deo, "Asphaltene aggregation in organic solvents," Journal of Colloid and Interface Science, vol. 271, pp. 212-219, 2004.

[23] X. Li, X. Fan, A. Askounis, K. Wu, K. Sefiane, and V. Koutsos, "An experimental study on dynamic pore wettability," Chemical Engineering Science, 2013.

[24] X. Li and X. Fan, "Experimental studies on multiphase flow in porous media and pore wettability," World Academy of Science, Engineering and Technology, vol. 74, pp. 739-743, 2013.

[25] B. H.-P. Cheong, T. W. Ng, Y. Yu, and O. W. Liew, "Using the meniscus in a capillary for small volume contact angle measurement in biochemical applications," Langmuir, vol. 27, pp. 11925-11929, 2011.

[26] M. F. Danisman, J. A. Calkins, P. J. A. Sazio, D. L. Allara, and J. V. Badding, "Organosilane self-assembled monolayer growth from supercritical carbon dioxide in microstructured optical fiber capillary arrays," Langmuir, vol. 24, pp. 3636-3644, 2008.

[27] M. M. Kohonen, "Engineered wettability in tree capillaries," Langmuir, vol. 22, pp. 3148-3153, 2006.

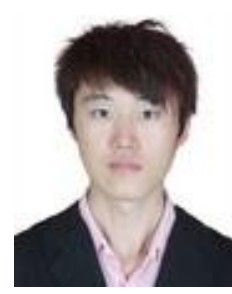

Xingxun Li was born in China on May $5^{\text {th }}, 1988$. He received his BEng degree in chemical engineering in the University of Edinburgh in 2010 and obtained MSc in advanced chemical engineering in Imperial College London in 2011. At present, he is doing PhD in multiphase flow and wettability under the supervision of Dr. Xianfeng Fan in the Institute of Materials and Processes, School of Engineering, University of Edinburgh, transport and wettability under the supervision of Dr. Xianfeng Fan in the Institute of Materials and Processes, School of Engineering, University of Edinburgh, UK. 